\title{
The past, present, and future of multiple wheat and maize breadbasket shocks
}

\section{Weston Anderson ( $\nabla$ weston@iri.columbia.edu )}

Columbia University https://orcid.org/0000-0003-3755-9943

\section{Walter Baethgen}

International Research Institute for Climate and Society, Columbia University

\section{Fabian Capitanio}

University of Naples https://orcid.org/0000-0003-0327-8019

\section{Philippe Ciais}

Laboratoire des Sciences du Climat et de l'Environnement https://orcid.org/0000-0001-8560-4943

\section{Benjamin Cook}

National Aeronautics and Space Administration

Gilberto Rocca da Cunha

Brazilian Agricultural Research Corporation

\section{Lisa Goddard}

International Research Institute

\section{Bernhard Schauberger}

Potsdam Institute for Climate Impact Research https://orcid.org/0000-0001-7917-0392

\section{Kai Sonder}

International Maize and Wheat Improvement Center https://orcid.org/0000-0001-9672-5361

\section{Guillermo Podestá}

University of Miami

\section{$M$ Van der Velde}

European Commission, Joint Research Centre https://orcid.org/0000-0002-9103-7081

\section{Liangzhi You}

International Food Policy Research Institute

\section{Article}

Keywords: simultaneous yield shocks, breadbaskets, wheat, maize, climate change, climate stress

Posted Date: August 26th, 2021

DOI: https://doi.org/10.21203/rs.3.rs-799323/v1 
License: (c) (i) This work is licensed under a Creative Commons Attribution 4.0 International License. Read Full License 


\section{The past, present, and future of multiple wheat and maize breadbasket shocks}

3 Weston Anderson ${ }^{1, *}$, Walter Baethgen ${ }^{1, *}$, Fabian Capitanio ${ }^{2}$, Philippe Ciais ${ }^{3}$, Benjamin I. Cook ${ }^{4,5}$,

${ }_{4}$ Gilberto Rocca da Cunha ${ }^{6}$, Lisa Goddard ${ }^{1}$, Bernhard Schauberger ${ }^{7,8}$, Kai Sonder ${ }^{9}$, Guillermo Podestá $^{10}$, Marijn van der Velde ${ }^{11}$, Liangzhi You ${ }^{12,13, *}$

${ }^{6}{ }^{1}$ International Research Institute for Climate and Society, The Earth Institute, Columbia University,

7 New York, NY, United States

${ }^{2}$ Department of Veterinary Medicine and Animal Production, University of Naples "Federico II",

$9 \quad$ Naples, Italy

${ }^{3}$ Laboratoire des Sciences du Climat et de l'Environnement, LSCE/IPSL, CEA-CNRS-UVSQ,

Universit Paris-Saclay, Gif-sur-Yvette, France

${ }^{4}$ NASA Goddard Institute for Space Studies, New York, NY, United States

${ }^{5}$ Lamont-Doherty Earth Observatory, Palisades, NY, United States

${ }^{6}$ Brazilian Agricultural Research Corporation, Embrapa, Passo Fundo, RS, Brazil

${ }^{7}$ University of Applied Sciences Weihenstephan-Triesdorf, Freising, Germany

${ }^{8}$ Potsdam Institute for Climate Impact Research (PIK), Potsdam, 14473, Germany

${ }^{9}$ International Maize and Wheat Improvement Center, Texcoco, Mexico, Texcoco, Mexico

${ }^{10}$ Rosenstiel School of Marine and Atmospheric Sciences, University of Miami, United States of America*, currently retired

${ }^{11}$ European Commission, Joint Research Centre, 21027 Ispra, Italy

${ }^{12}$ Macro Agriculture Research Institute, College of Economics and Management, Huazhong Agricultural University, Wuhan, Hubei 430070, China

${ }^{13}$ International Food Policy Research Institute, Washington, DC 20005, USA

*Corresponding authors: Weston@iri.columbia.edu, Baethgen@iri.columbia.edu,L.YOU@mail.hzau.edu.cn

Simultaneous yield shocks in multiple breadbaskets pose a potential threat to global food 
security, yet the historical risks and causes of such shocks are poorly understood. Here, we compile a dataset of subnational maize and wheat yield anomalies in $\mathbf{2 5}$ countries dating back to 1900 to better characterize the past, present, and future risk of multiple breadbasket shocks. We find that years in which at least half of all maize or wheat breadbaskets fall $10 \%$ (5\%) below expected yields has occurred in $\sim 2-3 \%(\sim 14-16 \%)$ of years over the last century. Importantly, multiple breadbasket shocks have been decreasing in frequency from 1930 to 2017. The EI Niño Southern Oscillation (ENSO) most strongly affects the probability of multiple maize breadbasket shocks, while the North Atlantic Oscillation (NAO) most strongly affects the probability of multiple wheat breadbasket shocks, each influencing the probability by up to $40 \%$. The effect of climate change on climate stress in maize and wheat breadbaskets is mixed; extreme heat will increase uniformly, agricultural soil moisture stress will remain constant or increase, but hydrological stress (as measured by runoff) will remain constant or decrease in breadbasket regions.

In recent decades international trade has become an increasingly important part of the global food system, with a majority of people now depending on food imports to meet daily caloric requirements ${ }^{1,2}$. Domestic food supply in heavily import-dependent countries is not always less stable than those that grow a larger fraction of their food ${ }^{3}$, but reliance on global food trade does present the unique risk in that production shocks in remote regions can lead to reduced availability or accessibility of food due to price spikes that make food unaffordable ${ }^{2,4-6}$. In this context, the possibility of multiple simultaneous breadbasket shocks presents a potential risk to food security $^{7-11}$.

Large-scale modes of climate variability - such as the El Niño Southern Oscillation (ENSO), the Indian Ocean Dipole (IOD), and the North Atlantic Oscillation (NAO) - present plausible mechanisms capable of affecting crop yields in multiple agricultural regions simultaneously? ${ }^{\text {? }}{ }^{12-15}$. These modes of climate variability affect regional-to-global atmospheric circulations that in turn connect the growing conditions of multiple agricultural regions and seasons to one-another ${ }^{14}$. While the potential for these modes to influence the probability of simultaneous yield shocks has 
been established, the strength of the effect has not been studied.

Characterizing long-term climate-related risks to maize and wheat breadbasket regions, however, is complicated by climate change, which is already affecting crop yields ${ }^{16-18}$ and is expected to continue altering the frequency of crop-relevant heat and moisture stress due to drying in the Mediterranean and South Africa ${ }^{19}$, an intensification of the Asian Monsoons ${ }^{20}$, and a wetting in Northern Europe and Southeast South America, where excess moisture damages crop yields regularly ${ }^{21,22}$. As with risks arising from climate variability, the potential threat is established but the magnitude of the stress that these diverse changes are placing on the potential for multiple breadbasket yield shocks is not well understood. Past research has demonstrated the importance of temperature-related risks ${ }^{8,10}$ but has either entirely excluded moisture stress from the analysis or has focused on precipitation, which fails to account for demand-side changes to the hydrologic cycle that result from increasing atmospheric moisture demand. Such studies are undoubtedly valuable contributions to the literature, but they do not provide a complete picture of present and future climate-related risks in breadbasket regions.

To date research on multiple climate-forced breadbasket shocks has been constrained by the necessity of using short statistical records of 38-47 years ${ }^{7,9,10,23}$ to characterize the causes, probability, and change in probability, of presumably rare events. With limited crop yield data available, studies detailing the physical causes of multiple breadbasket shocks have focused on case-studies ${ }^{11,13,15}$. Such case studies neither address the likelihood of such events occurring nor do they identify whether the proposed climate risks are those that are most relevant to food security, making it impossible to contextualize the importance of these scenario-based analyses.

Here, we construct a new century-long maize and wheat yield dataset and use a comprehensive set of climate stress variables to provide the most complete picture to date of how climate has affected multiple breadbasket shocks in the past, present, and may affect them in the future. We have compiled a dataset of subnational crop yield anomalies for maize and wheat consisting of over 34,000 observations from 132 subnational units in 25 countries dating back to 1900 (Fig. 
1), which we use to robustly estimate the probability of multiple breadbasket shocks, changes to that probability over the last 100 years, and to identify what has caused such shocks in the historical record. We furthermore use measures of growing season climate stress that account for both moisture supply and demand, as well as extreme maximum and minimum temperatures, to assess present and future climate risks in major wheat and maize breadbaskets.

History of multiple breadbasket shocks The relevance of multiple breadbasket shocks to food production differs by crop. For maize, the total production is dominated by yields in the United States and Northern China, which reflects the concentrated nature of maize production ${ }^{24}$. Joint maize breadbasket shocks between Northern China and the United States, therefore, are particularly relevant to global food production stability. For wheat, however, production is more evenly distributed among breadbaskets such that the net number of breadbasket regions with low as compared to high yield anomalies closely corresponds to the total breadbasket production anomaly (Fig. 2). In this context, the net number of breadbasket shocks is highly relevant to the global market. Throughout our analysis we define yield shocks as being either modest or major disruptions using a threshold of $5 \%$ or $10 \%$ below expected yields, respectively.

The historical incidence of widespread moderate disruptions among breadbaskets has not been uncommon, but widespread major disruptions have been exceedingly rare. We find that $\sim 3 \%$ ( $\sim 16 \%$ ) of years from 1930 to 2017 had four of eight maize breadbaskets experience major (moderate) disruptions (Fig. 2). For wheat, $\sim 2 \%(\sim 14 \%)$ of years had five out of nine breadbaskets experience major (moderate) disruptions simultaneously. While $14 \%-16 \%$ is a significant fraction of all years, a yield anomaly of 5\% below expected is only a modest shortfall in production.

Multiple breadbasket shocks have not been increasing in frequency over the last hundred years, regardless of which yield threshold is used. While previous results have found an increase in the frequency of soybean yield shocks across China and temperature-related risks across global breadbaskets during the 1967-2012 time period ${ }^{7,8}$, our results indicate that these risks have not translated into substantially more frequent maize or wheat breadbasket shocks (Fig. 2). In fact, 
the number of simultaneous maize and wheat shocks has been decreasing at both the $5 \%$ and $10 \%$ yield threshold, regardless of whether the trend is measured beginning in 1900 or 1931 - the earliest year for which all regions report data - and regardless of whether regions affected by World War 1 and 2 are removed. The decreasing trends are all significant at the $\mathrm{p}<0.05$ level with the exception of the frequency of wheat yield shocks at the 5\% yield threshold when the trend begins in 1931 and regions affected by World War 1 and 2 are removed, which is only significant at the $\mathrm{p}<0.1$ threshold. The overall trend towards stability for both moderate and major maize and wheat shocks is likely a result of the green revolution - the introduction of fertilizers, irrigation, and new varieties in many regions - that substantially increased crop yields and so made yield anomalies relatively more stable compared to total yields.

Despite the overall trend towards more stable crop yields, there are a number of decades and regions in which breadbasket shocks were relatively more common. For maize yields, the late 1940s and early 1950s stand out as a time with many breadbasket shocks, with crops failing across China, India, Europe, and Southeast South America (Fig. 2). When considering the full period, maize yields in South Africa are particularly volatile. For wheat, the late 1940s through 1980 stand out as often having 3-4 breadbasket shocks in a year. The US and China in particular experience multi-year crop shocks during this period. In the modern period the volatility of wheat yields in the US and Australia remains high.

At the global scale, we characterize the complete risk profile of multiple breadbasket shocks in Figure 3, which presents the likelihood of a given year having between one and eight regions with crop yield losses of between $1 \%$ and $10 \%$. Only rarely do over half of the breadbasket regions report crop losses at all, let alone losses greater than 10\%. But at least one breadbasket region reported a loss of over $10 \%$ in at least $60 \%$ of years. When comparing the more recent period to the earlier period, maize shocks occurring in 2-4 regions simultaneously became less probable at all levels of crop yield loss, while there was little change in maize yield surpluses. Similar to maize, the occurrence of 2-4 simultaneous wheat shocks became up to $30 \%$ less frequent in the later period as compared to the earlier period. Simultaneous wheat surpluses of over $6 \%$, however, 
also became less frequent in the later period.

Climate-drivers of multiple breadbasket shocks Figures 1 and 2 indicate that in over a century, major disruptions have rarely occurred in over half of all reporting breadbaskets simultaneously, lending credibility to the notion that producing crops in regions with relatively uncorrelated risks buffers against the probability of multiple simultaneous crop yield shocks. However, as pointed out by Anderson et al. (2019) ${ }^{13}$, global modes of climate, such as the El Niño Southern Oscillation (ENSO), may organize weather in such a way that increases the likelihood of simultaneous crop yield shocks.

Using our century-long yield dataset, we find that modes of climate variability have had a large effect on the probability of joint crop shocks in pairs of breadbasket regions. The probability of joint crop shocks differ by up to $40 \%$ in opposite phases of major climate modes (Fig. 4). For both wheat and maize, the Indian Ocean Dipole (IOD) and, to a lesser extent, ENSO, affect crop yields in a balanced manner, increasing the probability of joint crop shocks in some breadbaskets and reducing the probability of joint crop yield shocks elsewhere. The North Atlantic Oscillation (NAO), however, has a unidirectional influence on the probability of joint wheat or maize breadbasket shocks, although its influence on maize is limited (Fig. 4).

El Niño increases the probability of joint wheat yield shocks between pairs of countries that include Australia, the Mediterranean, or Southeast South America by $0-40 \%$ with the strongest influence on the joint probability of moderate shocks in Australia and the Mediterranean. El Niño primarily decreases the probability of joint crop yield shocks between the Southern Great Plains and Northern North America by $\sim 10-45 \%$. For maize, El Niños increase the probability of joint maize yield shocks in South Africa, Northern China, and India by $\sim 0-40 \%$ with its strongest effect on the joint probability of shocks in South Africa and Northern China. El Niños decrease the probability of joint maize yield shocks in the United States, Southeast South America, and Southern China by $\sim 0-35 \%$. Of particular relevance to global maize production are the offsetting ENSO teleconnections in the US and Northern China ${ }^{14}$, such that joint yield shocks of the US and 
Northern China breadbaskets are unaffected.

The IOD has an effect similar to that of ENSO in many regions, although it has a statistically significant effect on fewer pairs of regions (Fig. 4). The strongest influence of the IOD on joint wheat yield shocks is between pairs of regions that include Australia, while for maize it most strongly affects the probability of joint crop yield shocks in pairs of regions that include South Africa or India.

The NAO does not significantly affect as many regions as does ENSO, but the direction of its influence is uniform (Fig. 4). Positive NAO events reduce the probability of joint wheat yield shocks in regions that include the Western Mediterranean, Northern China, and India by $\sim 0-25 \%$, while negative NAO events increase the probability of joint wheat yield shocks in these regions. Only in Europe and Northern China does a positive NAO increase the probability of a moderate joint wheat yield shocks and even in this pair of regions the effect is weak ( $\sim 5 \%$ change). The NAO affects very few maize breadbaskets, although it does affect the probability of joint maize yield shocks in three pairs of regions.

At the global scale, we find that the NAO and ENSO affect the probability of multiple breadbasket shocks by up to $40 \%$, while the IOD has only limited statistically significant effects. The negative phase of the NAO is most strongly associated with an increased probability of simultaneous wheat breadbasket shocks despite ENSO affecting a larger geographic area and a greater number of regions than does the NAO, which only affects the climate of the northern hemisphere. That the NAO affects the probability of multiple wheat breadbasket shocks more strongly than ENSO is a result of its unidirectional influence on the probability of joint wheat shocks, as described above.

Climate change and water stress in breadbasket regions We use our historical crop yield dataset in combination with measures of water and temperature stress to characterize how climate stresses have and will affect breadbasket regions. Following from the results of Figures 4 and 
5, we focus on ENSO as the primary mode of variability affecting multiple maize shocks and the NAO as the primary mode affecting multiple wheat shocks.

We identify damaging conditions by constructing breadbasket-specific thresholds of damaging temperature or moisture stress (excess or deficit) during the growing season using the $\sim 100$ years of subnational data available. We characterize possible future climate conditions using CMIP5 model projections of mean-state changes to surface temperature, soil moisture (agricultural moisture stress), or runoff (hydrological moisture stress), averaged over the growing season, added to the full distribution of observed climate variability in each region (see Methods for details). Using measures of soil moisture and runoff allows us to account for changes in both atmospheric moisture demand and moisture supply that may affect crop yields. Using measures of temperature stress that include both high and low temperature stress allows us to characterize the changing distribution of temperature at both extremes. We use our ensemble to investigate changes in climate stress and contextualize them against the historical variability that those same regions presently experience

We find that temperature stress in breadbasket regions will uniformly increase, but the change in agricultural and hydrological moisture stress depends on crop and forcing scenario. For wheat, the breadbasket areas experiencing temperature stress will increase by 100-200\%, covering up to $80 \%$ of all breadbasket areas by the end of the century. The marginal increase in hydrological moisture stress will remain smaller than differences due to internal variability due to the NAO, but the much larger increase in agricultural moisture stress will considerably exceed the observed envelope of natural variability in both forcing scenarios. For maize, temperature stress will increase by three-fold even in the RCP 4.5 scenario, reaching near-complete coverage of all breadbasket areas in the RCP 8.5 scenario. Note that empirically-derived damaging temperature thresholds could not be established for Mexico based on our data, but it is likely that temperatures will be damaging in Mexico as well in this scenario. Hydrological moisture stress in maize breadbasket regions, however, will decrease by $\sim 30-50 \%$ in RCP 4.5 and 8.5 forcing scenarios. Agricultural moisture stress will increase only in the high-forcing scenario, but then it will increase by over 
$100 \%$.

Discussion Using our century-long dataset of national and subnational crop yields, we find that the likelihood of multiple maize and wheat yield shocks is affected by climate variability and has not yet increased over the last century, but may yet as a result of climate change. The probability of multiple breadbasket yield shocks actually decreased for both maize and wheat from 1930 to 2017, likely the result of improved cropping systems technology and management that led to maize and wheat yield increases relative to the magnitude of yield shortfalls in poor production years.

Climate variability affects both the spatial pattern and overall level of risk for multiple breadbasket yield shocks. ENSO, the NAO, and the IOD all affect the probability of multiple maize or wheat yield shocks in pairs of regions by up to $40 \%$. While ENSO affects the probability of joint yield shocks in the greatest number of regions for both maize and wheat, both ENSO and the IOD provide some balance by increasing the probability of joint shocks in some regions and decreasing the probability in other regions.

The NAO, however, unidirectionally increases or decreases the probability of joint yield shocks in breadbasket regions, and as a result most strongly affects the overall number of wheat breadbasket shocks globally. This finding is somewhat surprising provided that the NAO affects cropped areas only in the Northern Hemisphere, while ENSO affects cropped areas globally, and that a given phase of the NAO forces both wet and dry teleconnections in major wheat growing regions $^{25}$. The dissonance between precipitation and wheat yield NAO teleconnections is likely because a positive phase of the NAO reduces precipitation in many of the same locations where wheat yields benefit from irrigation and have done so for nearly a century ${ }^{26,27}$ (see supplemental text and SI Fig. 3).

By the end of the century, climate change will compound the stress that ENSO, the NAO, and the IOD place on breadbaskets. Consistent with past literature, we find that the risk of damaging maximum temperatures increases for all breadbaskets, and does so more strongly in maize than in 
wheat breadbaskets. Changes to hydroclimate stress, however, will depend on the crop, variable, and forcing scenario. We consider both soil moisture and runoff, which may be captured and used for crop water management. For wheat, although damagingly dry soil moisture conditions are projected to expand in both high and moderate forcing scenarios, runoff conditions will largely remain constant. For maize, damagingly dry soil moisture conditions will only increase in the high forcing scenario while runoff during the growing season will actually become more favorable. These contrasting results imply that for both maize and wheat breadbaskets, water management may become increasingly important as soils dry but, in some regions, runoff increases. These results indicate that major breadbaskets will experience warmer growing seasons with drier soil moisture but constant or increased water available from runoff.

Our results demonstrate the importance of considering both climate variability and change as a factor influencing the probability of simultaneous maize and wheat yield shocks in major breadbaskets. Climate variability, in particular the NAO and ENSO, affect the probability of both joint yield shocks in pairs of major breadbaskets and the overall number of yield shocks. The importance of understanding and mitigating climate extremes in major breadbaskets will become increasingly important as a means of continuing to stabilize food production over the next century as climate change increases the temperature and soil moisture stress during growing seasons in major breadbaskets.

\section{Methods}

Data Crop yield data are taken from the Twentieth Century Crop Statistics Data Set version 1, which is an aggregation of existing, publicly available crop statistics from national statistics and agricultural agencies for 27 countries. The data set consists of national or subnational maize and wheat production, yield, and harvested area data for all available years from 1900-2017, including digitizing new statistics in Italy, Spain, Indonesia, China, Mexico, Uruguay, Chile, Sweden, and Morocco. Full documentation, including the original sources of data for each country can be found in Anderson et al., submitted. All data is at the national or administrative level one unit, 
with the exception of Italy, for which data was only available for seven agriculturally-relevant administrative level two units. These seven administrative level two units collectively accounted for 52\% and 68\% of total wheat and maize production, respectively, in Italy in 2010.

To understand how potentially damaging hydroclimate conditions have varied with time over the past century we use a collection of hydroclimate variables that account for both supply and demand of moisture, including land surface model-based estimates of surface-level soil moisture and reconstructed estimates of runoff. For our land surface model-based estimates of soil moisture we use Noah model output from the Global Land Data Assimilation System (GLDAS) 2.0 over 1950-2009 ${ }^{28,29}$. For runoff data from 1902-2014, we use global monthly reconstructed estimates of runoff from the GRUN dataset, which is based on a statistical model incorporating reanalysis precipitation and temperature information to predict runoff ${ }^{30}$. When evaluated against long records of discharge observations, GRUN outperforms many state-of-the art hydrological models.

To calculate potentially damaging temperatures, we calculate both damaging maximum temperature and damaging minimum temperature during the crop growing season for maize and wheat in each location. Crop yields respond nonlinearly to extreme heat, indicating the importance of separating out the effect of high maximum temperatures ${ }^{31}$. To capture damaging extreme maximum temperatures, we calculate killing degree days as the sum of the degree to which daily maximum temperatures exceed an optimum threshold $\left(29^{\circ} \mathrm{C}\right.$ for maize or $26^{\circ} \mathrm{C}$ for wheat) over the growing season for each crop $^{32}$. If the maximum daily temperature does not exceed the threshold it is counted as zero. Likewise, to calculate damaging extreme minimum temperatures we calculate chilling degree days as the sum of the degree to which daily minimum temperatures fall below an optimum threshold $\left(8^{\circ} \mathrm{C}\right.$ for maize or $0^{\circ} \mathrm{C}$ for wheat) over the growing season for each crop.

To understand how climate change may affect the climate in breadbasket regions, we use a multi-model ensemble for two hydroclimate variables and the two temperature variables from two different representative concentration pathways in CMIP5 models. We choose three hydroclimate variables that are both widely available in climate model output, and that account for both supply and demand of moisture: surface runoff (variable: mrros) and surface-level soil moisture (variable: 
mrsos). The surface-level soil moisture variable is comparable to the land surface model-based estimates of surface-level soil moisture used in the historical analysis. We calculate the multimodel mean for each hydroclimate variable in CMIP5 RCP 4.5 and RCP 8.5 as follows. First we convert each future projection ensemble member to a z-score using the mean and standard deviation of the corresponding historical model ensemble. We next average across the first five available ensemble members within each model, followed by averaging across all models. We include the following models in our analysis: CanESM2, CCSM4, CNRM-CM5, GFDL-ESM2M, GISS-E2R, HadGEM2-CC, HadGEM2-ES, inmcm4, IPSL-CM5A-LR, IPSL-CM5A-MR, MIROC-ESM, MIROC-ESM-CHEM, MIROC5, MRI-CGCM3, and NorESM1-M. This procedure produces local z-score estimates of changes in hydroclimate stress surface runoff and surface soil moisture between the historical period and each year of the future projection. To calculate the climate projections for the maximum and minimum temperature variables, we calculate the multi-model mean difference of absolute temperature in the climate change and historical period for each month. We then add these monthly values of maximum or minimum daily temperature to each day in the month of the daily maximum or minimum daily temperatures before recalculating the killing degree days and chilling degree days in each season at each location.

Methods The Twentieth Century Crop Statistics Data Set includes absolute yields and yield anomalies calculated using a variety of methods to remove crop yield trends to test for sensitivity, including a low-frequency Gaussian filter with a kernel density of five years and eight years, a low frequency Lowess filter, and a simple nine and fifteen-year running mean. In this analysis we use the low-frequency Gaussian filter with a kernel density of five years, which is similar to the fifteen year running mean without the undesirable property of requiring that we drop the first and last seven years of the time series. Following the calculation of the absolute yield anomalies, we convert yield anomalies at the subnational scale to percent anomalies by dividing the absolute yield anomalies by the expected yield. These percent yield anomalies are used in spatial maps of teleconnections associated with ENSO, the IOD, and the NAO.

To define multiple breadbasket shocks we first aggregate crop statistics up to the breadbasket 
level. We define breadbaskets by combining considerations of production system with temperature and moisture regimes in the areas for which we have data, resulting in eight breadbaskets for maize and nine breadbaskets for wheat. This process is subjective, and relies on the expert guidance of the author team for considerations of both climate and agricultural systems. Once the breadbaskets are defined, we evaluate how risks to these static breadbaskets have evolved over time. The goal of this analysis is not to evaluate how breadbaskets have shifted over time, but rather to rigorously evaluate risks to present-day breadbaskets. As such, we aggregate absolute crop yield anomalies up to a time series of production anomalies for each breadbasket using static harvested area measurements averaged over 2005-2010 to represent present-day production systems. This results in a single time series for each breadbasket, which is converted to a percent yield anomaly as described earlier for the subnational and national-scale time series.

To test whether multiple breadbasket shocks have increased in the most recent period compared to earlier reporting periods we use a two-tailed Kolmogorov-Smirnov test to compare the distribution of the number of regions with either maize or wheat yield shocks at either a $5 \%$ or $10 \%$ level. We test the sensitivity of the result to the choice of time period by selecting combinations of starting periods between 1930-1970 and 1940-1980 as compared to the more recent portion of the record. We test also the sensitivity to measuring the number of breadbasket shocks vs the percent of reporting breadbaskets, and test whether including the years removed due to World War I and II affect the results. We find the results are relatively insensitive to these choices.

When considering multiple breadbasket shocks that may result from natural abiotic or biotic factors, we seek to exclude the effects of World War I and II from our results, although these events do not change our overall conclusions if they were to be included. To remove the influence of World War I from our results, we exclude the years 1914-1919 in the Mediterranean and Europe breadbaskets (regions four and five for wheat, and region four for maize). To remove the influence of World War II, we exclude the years 1940-1945 from the Mediterranean, Europe, India, and both North and South China breadbaskets (regions 4-8 for wheat and 4, 6, 7, and 8 for maize). Excluded data is shown in light blue and hatched in Figure 2. From the breadbasket percent 
yield anomaly time series we calculate the number of breadbasket yield shocks or surpluses using thresholds of both 5\% and 10\%, and count either the number or percent of reporting regions with shocks and surpluses. This data is used to calculate the return period curves. To calculate the relative probability of a certain number of crop shocks occurring in a given phase of a particular climate mode, we compare the probability of at least that many shocks occurring during years that experience the climate mode compared to the overall probability of that many crop shocks occurring based on all available years.

To calculate the relative probability of joint yield shocks in pairs of regions and of multiple yield shocks globally during specific modes of climate variability, we calculate the probability of an event occurring in each phase of the climate mode (e.g. ENSO, NAO, IOD) and difference the two. To test for statistical significance we randomly draw $\mathrm{n}$ samples without replacement from the historical record for each phase of each climate mode, where $\mathrm{n}$ is the number of observed years in which the given climate mode is in a particular phase, and repeat the above calculation. We repeat this process 1000 times to produce a distribution for each calculated probability and identify the 5th and 95th percentiles of each to use to test statistical significance.

To estimate potentially damaging climate conditions that occurred historically, we aggregate the historical climate moisture availability and temperature stress variables to the subnational scale averaged across the relevant crop growing seasons, defined using Sacks et al. $2010^{33}$, and the subnational cropped region, defined as any cell having at least 10,000 ha of planted maize or wheat area. We then convert each time series to a z-score by subtracting the mean and dividing by the standard deviation. This produces, for each subnational unit, several standardized measures of climate stress, which we relate to crop yield anomalies. We first create dataframes at the regional level, in which each observation consists of a z-score for climate stress in a particular subnational unit during a particular year in a given region and the corresponding yield anomaly for that year. We then relate the climate stress covariates to the yield anomalies using a generalized additive model (GAM) for each region. We choose a GAM structure because it is a flexible, nonlinear model and as such can estimate climate conditions that would be damaging to yields due to both excess 
or deficit temperature and moisture. We restrict the complexity of each GAM model to include a maximum of six spline terms. From the GAM model fits we estimate potentially damaging climate conditions as the $\mathrm{x}$-axis crossing point for each GAM model term. See the supplementary information and SI Figures 4-11 for further details.

To project envelopes of possible future climate stress we overlay observed variability onto multimodel mean estimates of projected changes in stress. For temperature stress, we add a constant monthly mean to daily maximum or minimum temperature data before re-calculating the killing degree days or chilling degree days for each crop and each season. For hydroclimate stress, we first smooth the multimodel mean estiamtes of projected hydroclimate stress using a 20 year running window. We then construct an envelope of plausible hydroclimate stress by adding the full historical record of z-scores of hydroclimate stress to each timestep, yielding an ensemble of with a number of values equal to the number of years in the observational record for each projected year and location. We then estimate within each ensemble member the fraction of each breadbasket area that exceeds the thresholds identified as damaging using the GAM models from above, providing us with estimates of total breadbasket areas under stress in any given year in the projections under RCP 4.5 and 8.5. Breadbasket areas to be used in the calculation are defined as those within the breadbasket bounding boxes (SI Fig.12) and having at least 10,000 ha of harvested area.

Acknowledgements This work was funded by ACToday, the first of Columbia University's World Projects.

1. Porkka, M., Kummu, M., Siebert, S. \& Varis, O. From food insufficiency towards trade dependency: a historical analysis of global food availability. PloS one 8, e82714 (2013).

2. Puma, M. J., Bose, S., Chon, S. Y. \& Cook, B. I. Assessing the evolving fragility of the global food system. Environmental Research Letters 10, 024007 (2015).

3. d'Amour, C. B. \& Anderson, W. International trade and the stability of food supplies in the global south. Environmental Research Letters 15, 074005 (2020). 
4. d'Amour, C. B., Wenz, L., Kalkuhl, M., Steckel, J. C. \& Creutzig, F. Teleconnected food supply shocks. Environmental Research Letters 11, 035007 (2016).

5. Heslin, A. et al. Simulating the cascading effects of an extreme agricultural production shock: global implications of a contemporary us dust bowl event. Frontiers in Sustainable Food Systems 4, 26 (2020).

6. Marchand, P. et al. Reserves and trade jointly determine exposure to food supply shocks. Environmental Research Letters 11, 095009 (2016).

7. Gaupp, F., Hall, J., Hochrainer-Stigler, S. \& Dadson, S. Changing risks of simultaneous global breadbasket failure. Nature Climate Change 10, 54-57 (2020).

8. Gaupp, F., Hall, J., Mitchell, D. \& Dadson, S. Increasing risks of multiple breadbasket failure under 1.5 and 2 c global warming. Agricultural Systems 175, 34-45 (2019).

9. Mehrabi, Z. \& Ramankutty, N. Synchronized failure of global crop production. Nature ecology \& evolution 3, 780-786 (2019).

10. Tigchelaar, M., Battisti, D. S., Naylor, R. L. \& Ray, D. K. Future warming increases probability of globally synchronized maize production shocks. Proceedings of the National Academy of Sciences 115, 6644-6649 (2018).

11. Janetos, A. et al. The risks of multiple breadbasket failures in the 21st century: a science research agenda (2017).

12. Iizumi, T. et al. Impacts of el niño southern oscillation on the global yields of major crops. Nature communications 5 (2014).

13. Anderson, W., Seager, R., Baethgen, W., Cane, M. \& You, L. Synchronous crop failures and climate-forced production variability. Science advances 5, eaaw1976 (2019).

14. Anderson, W., Seager, R., Baethgen, W. \& Cane, M. Trans-pacific enso teleconnections pose a correlated risk to agriculture. Agricultural and forest meteorology 262, 298-309 (2018). 
15. Singh, D. et al. Climate and the global famine of 1876-78. Journal of Climate 31, 9445-9467 (2018).

16. Ortiz-Bobea, A., Ault, T. R., Carrillo, C. M., Chambers, R. G. \& Lobell, D. B. Anthropogenic climate change has slowed global agricultural productivity growth. Nature Climate Change 11, 306-312 (2021).

17. Moore, F. C. \& Lobell, D. B. The fingerprint of climate trends on european crop yields. Proceedings of the National Academy of sciences 112, 2670-2675 (2015).

18. Lobell, D. B. et al. Prioritizing climate change adaptation needs for food security in 2030. Science 319, 607-610 (2008).

19. Seager, R. et al. Climate variability and change of mediterranean-type climates. Journal of Climate 32, 2887-2915 (2019).

20. Seth, A. et al. Monsoon responses to climate changes-connecting past, present and future. Current Climate Change Reports 5, 63-79 (2019).

21. Olesen, J. E. et al. Impacts and adaptation of european crop production systems to climate change. European Journal of Agronomy 34, 96-112 (2011).

22. Zampieri, M., Ceglar, A., Dentener, F. \& Toreti, A. Wheat yield loss attributable to heat waves, drought and water excess at the global, national and subnational scales. Environmental Research Letters 12, 064008 (2017).

23. Kornhuber, K. et al. Amplified rossby waves enhance risk of concurrent heatwaves in major breadbasket regions. Nature Climate Change 10, 48-53 (2020).

24. Ben-Ari, T. \& Makowski, D. Decomposing global crop yield variability. Environmental Research Letters 9, 114011 (2014).

25. Baek, S. H. et al. Precipitation, temperature, and teleconnection signals across the combined north american, monsoon asia, and old world drought atlases. Journal of climate 30, 71417155 (2017). 
26. Siebert, S. et al. A global data set of the extent of irrigated land from 1900 to 2005. Hydrology and Earth System Sciences 19, 1521-1545 (2015).

27. Wang, X. et al. Global irrigation contribution to wheat and maize yield. Nature Communications 12, 1-8 (2021).

28. Rodell, M., Houser, P., Jambor, U., Gottschalck, J. et al. The global land data assimilation system. Bulletin of the American Meteorological Society 85, 381 (2004).

29. Rodell, M. \& Kato Beaudoing, H. Gldas noah land surface model 14 monthly 1.0 x 1.0 degree version 2.0,version 020. Tech. Rep., NASA/GSFC/HSL (12.01.2013), Greenbelt, Maryland, USA:Goddard Earth Sciences Data and Information Services Center (GES DISC). doi:10.5067/QN80TO7ZHFJZ (2015).

30. Ghiggi, G., Humphrey, V., Seneviratne, S. I. \& Gudmundsson, L. Grun: an observation-based global gridded runoff dataset from 1902 to 2014. Earth System Science Data 11, 1655-1674 (2019).

31. Schlenker, W. \& Roberts, M. J. Nonlinear temperature effects indicate severe damages to us crop yields under climate change. Proceedings of the National Academy of sciences 106, 15594-15598 (2009).

32. Sánchez, B., Rasmussen, A. \& Porter, J. R. Temperatures and the growth and development of maize and rice: a review. Global change biology 20, 408-417 (2014).

33. Sacks, W. J., Deryng, D., Foley, J. A. \& Ramankutty, N. Crop planting dates: an analysis of global patterns. Global Ecology and Biogeography 19, 607-620 (2010). 

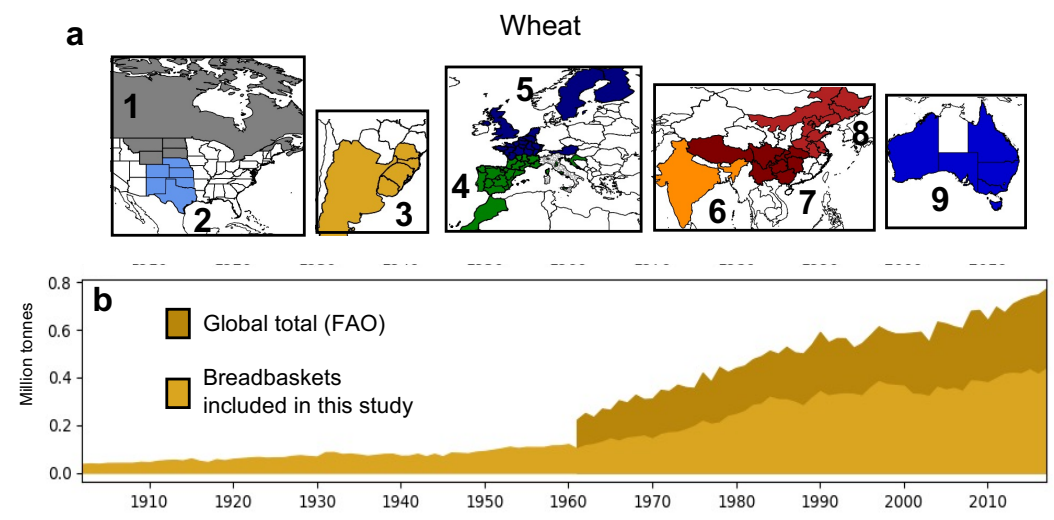

c
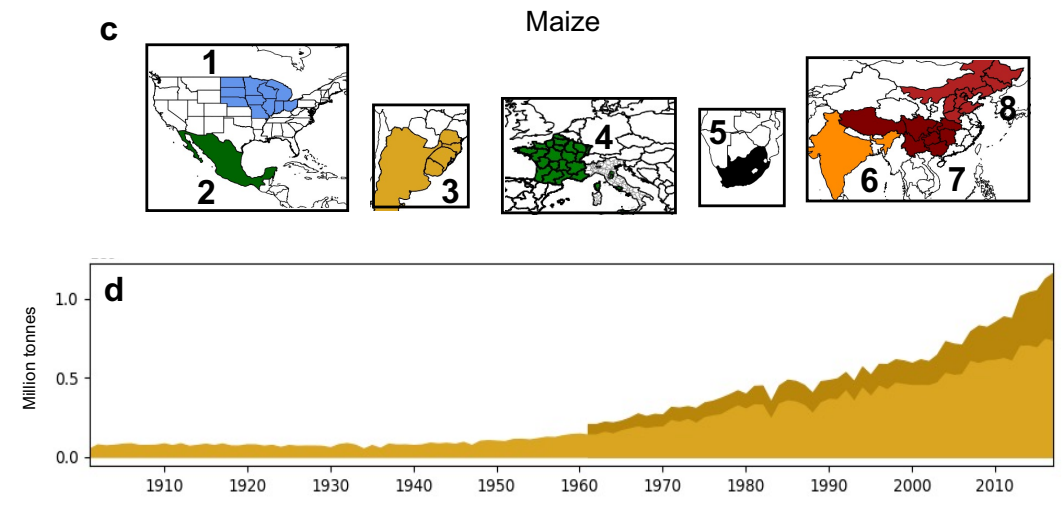

Figure 1: Breadbasket regions and crop production. Wheat breadbasket regions included in this analysis with selected wheat-growing political units colored for (a): Northern North America (1), Southern United States Great Plains (2), Southeast South America (3), Mediterranean (4), Northern Europe (5), India (6), Southern China (7), Northern China (8), and Australia (9). Total wheat production included in the wheat breadbasket regions (light gold) compared to total global wheat production according to FAOSTAT (dark gold; b). Maize breadbasket regions included in this analysis: Midwest United States (1), Mexico (2), Southeast South America (3), Italy and France (4), South Africa (5), India (6), Southern China (7), Northern China (8). Total maize production included in the wheat breadbasket regions (light gold) compared to total global wheat production according to FAOSTAT (dark gold; d) 

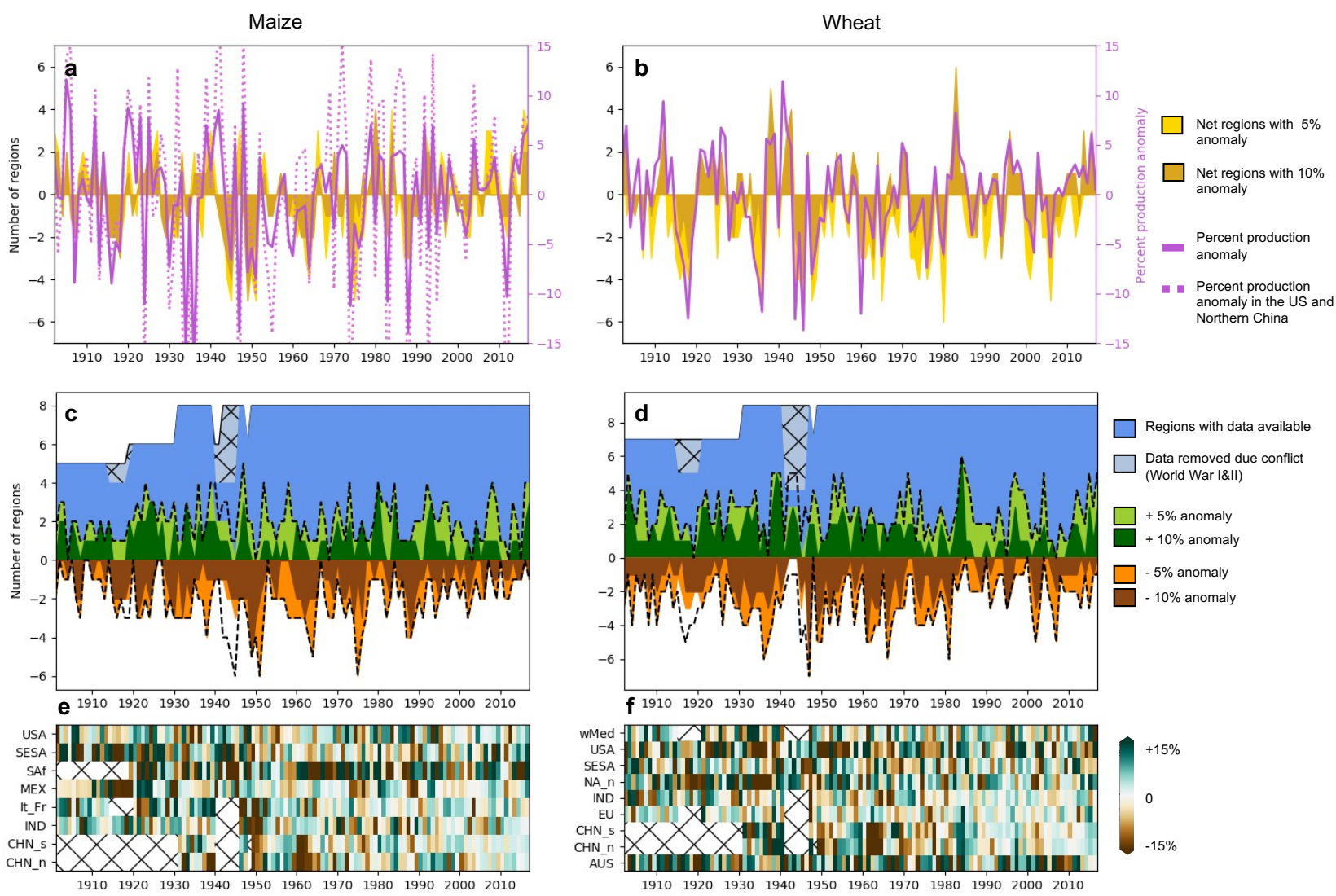

Figure 2: Breadbasket yield deficits and surpluses. Total production anomaly in breadbasket regions and net number of breadbasket shocks (calculated as the number of regions with yield surpluses minus the number with deficits) defined at the 5\% and $10 \%$ level (a,b). Number of breadbasket regions reporting regional yield anomalies deviating by at least $5 \%$ or $10 \%$ from expected yields $(\mathrm{c}, \mathrm{d})$ with positive values indicating regions with surpluses and negative values indicating regions with deficits. Total number of regions reporting data (solid blue) and regions with data available but excluded due to World War I and II (hatched blue; c,d). Dotted lines in a-d indicate a sensitivity analysis for the 5\% yield anomaly level in which no data is removed due to World War I or II. Regional yield anomalies for each individual breadbasket (e,f). 

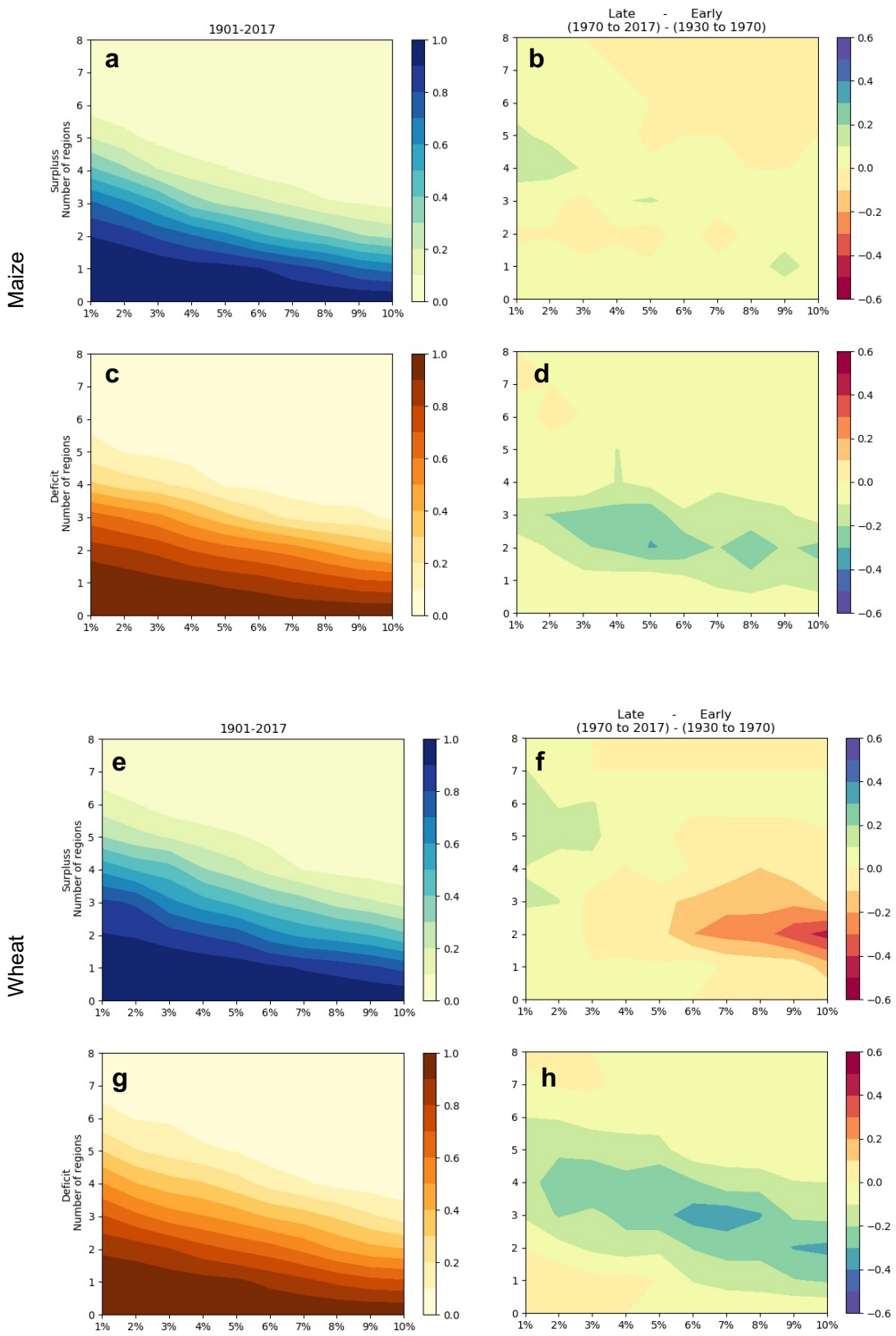

Figure 3: Regional crop yield surplus and deficit exceedance curves. Exceedance probabilities for maize surpluses (a) and shocks (c) of between $1 \%$ and $10 \%$ occurring simultaneously in between 0 and 8 breadbasket regions over the entire 1901-2017 time period. Difference between the probabilities of exceedance in the earliest period for which all regions report data and the more recent period for maize surpluses (b) and shocks (d). Panels e-h as in a-d, except for wheat breadbaskets. 


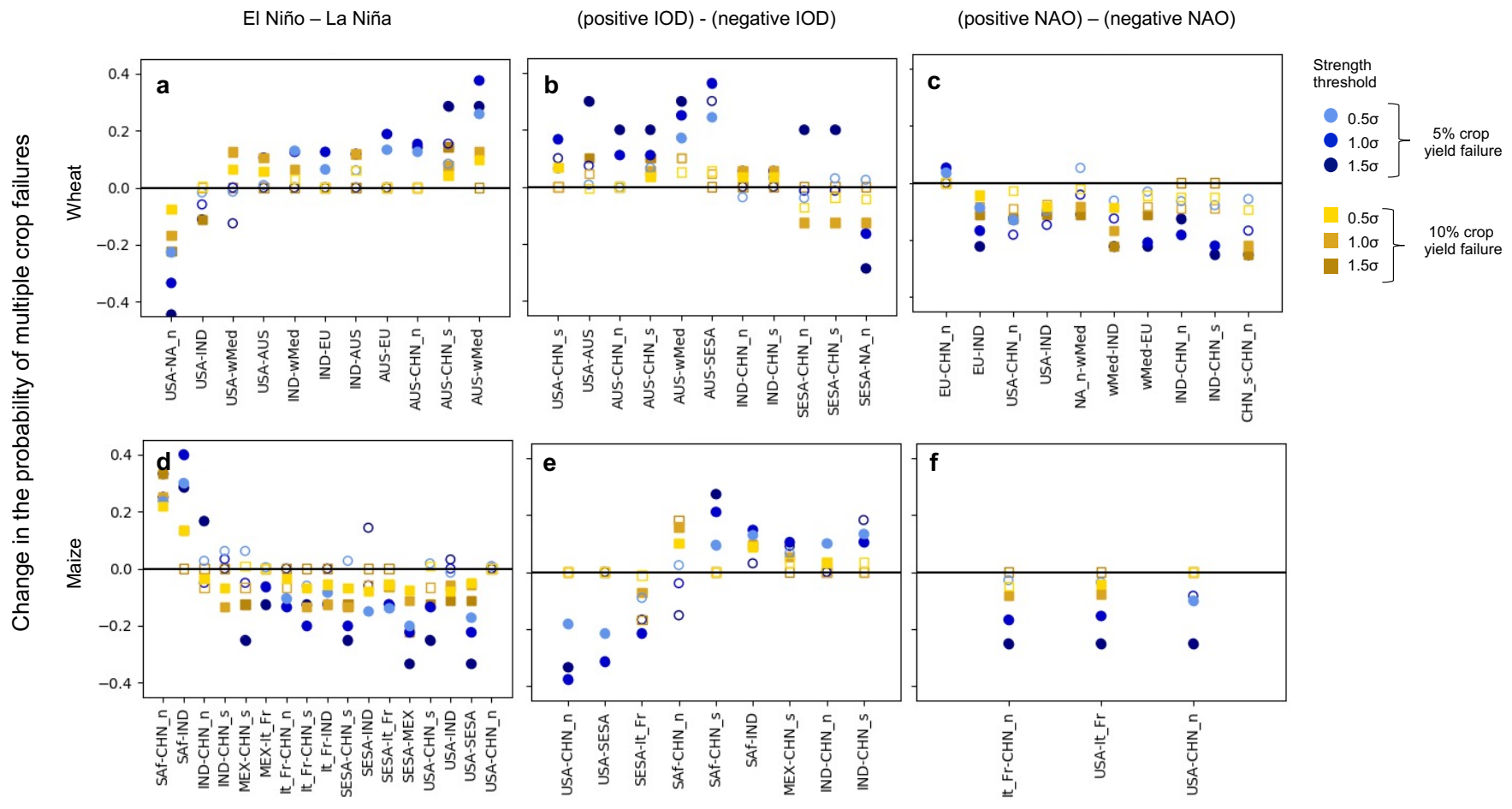

Figure 4: Probability of joint crop yield shocks in breadbasket regions. Difference in the probability of joint crop yield shocks for pairs of breadbasket regions during the positive minus the negative phase of the El Niño Southern Oscillation (a,d), the North Atlantic Oscillation (b,e), and the Indian Ocean Dipole (c,f). All pairs with at least two statistically significant points $(\mathrm{p}<0.05$ based on a bootstrap test for significance, see Methods) are shown. USA-Northern China pair is additionally included for maize. Filled symbols indicate statistical significance, unfilled symbols indicate that differences were not significant at the $95 \%$ level. 


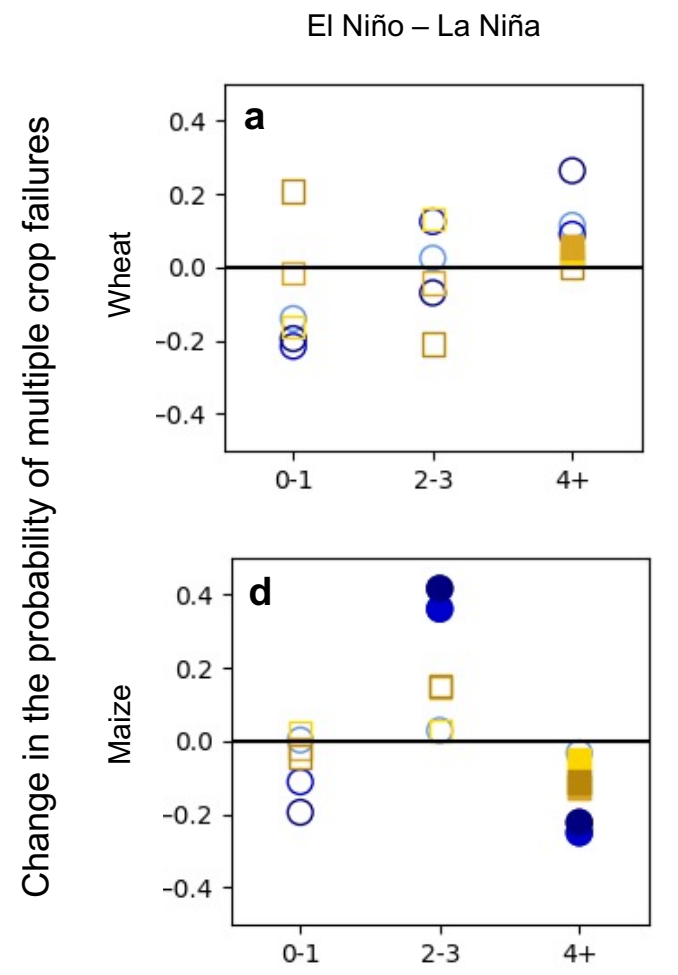

(positive IOD) - (negative IOD) (positive NAO) - (negative NAO)
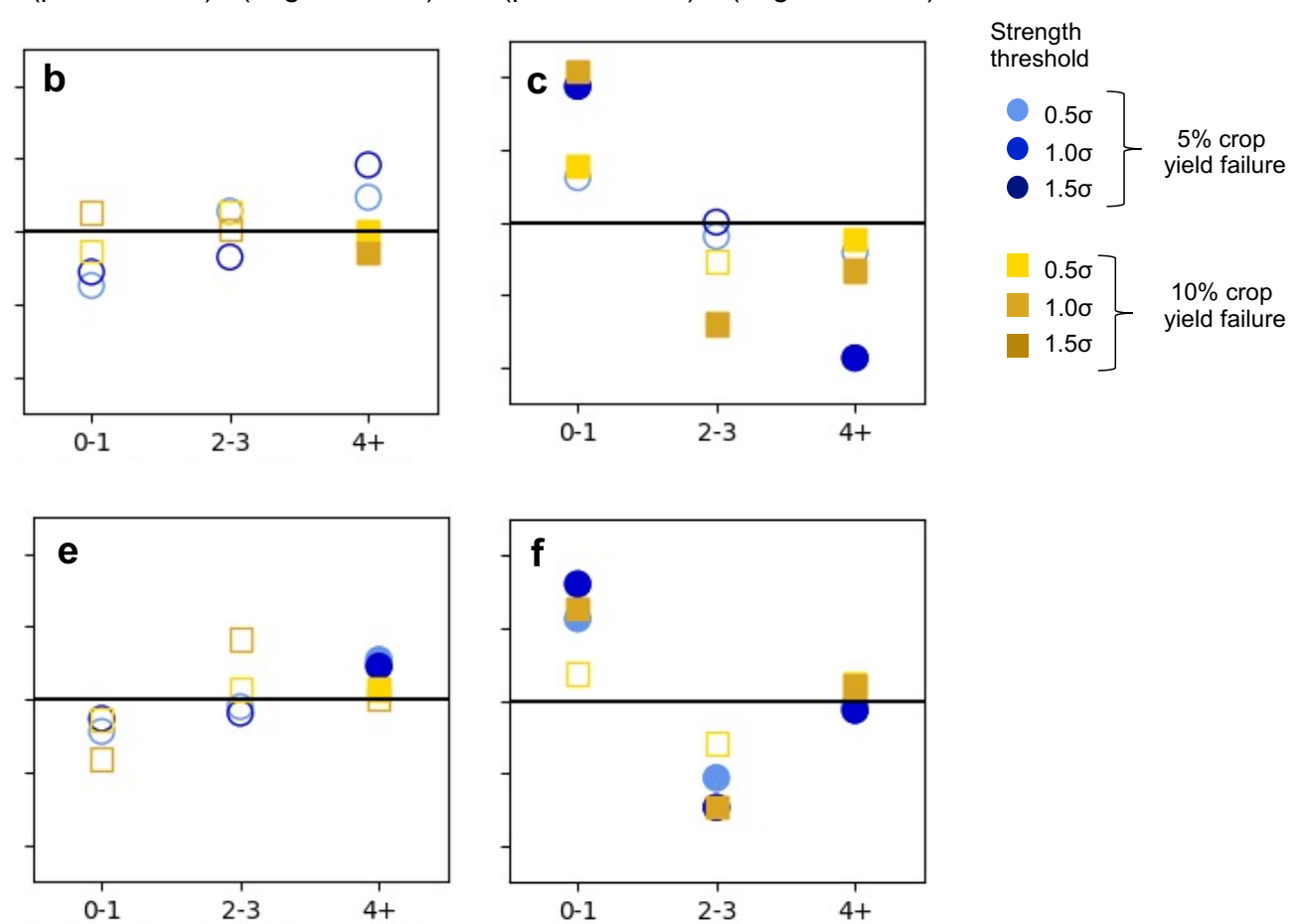

Number of regions with crop failures

Figure 5: Probability of multiple crop shocks. Difference in the probability, compared to the complete record, of a year experiencing $0-1,2-3$, or over 4 breadbasket shocks at the $5 \%$ or $10 \%$ yield threshold during the positive minus the negative phase of the El Niño Southern Oscillation $(a, b)$, the North Atlantic Oscillation (c,d), or the Indian Ocean Dipole (e,f). Filled symbols indicate statistical significance, unfilled symbols indicate that differences were not significant at the $95 \%$ level (see Methods). 

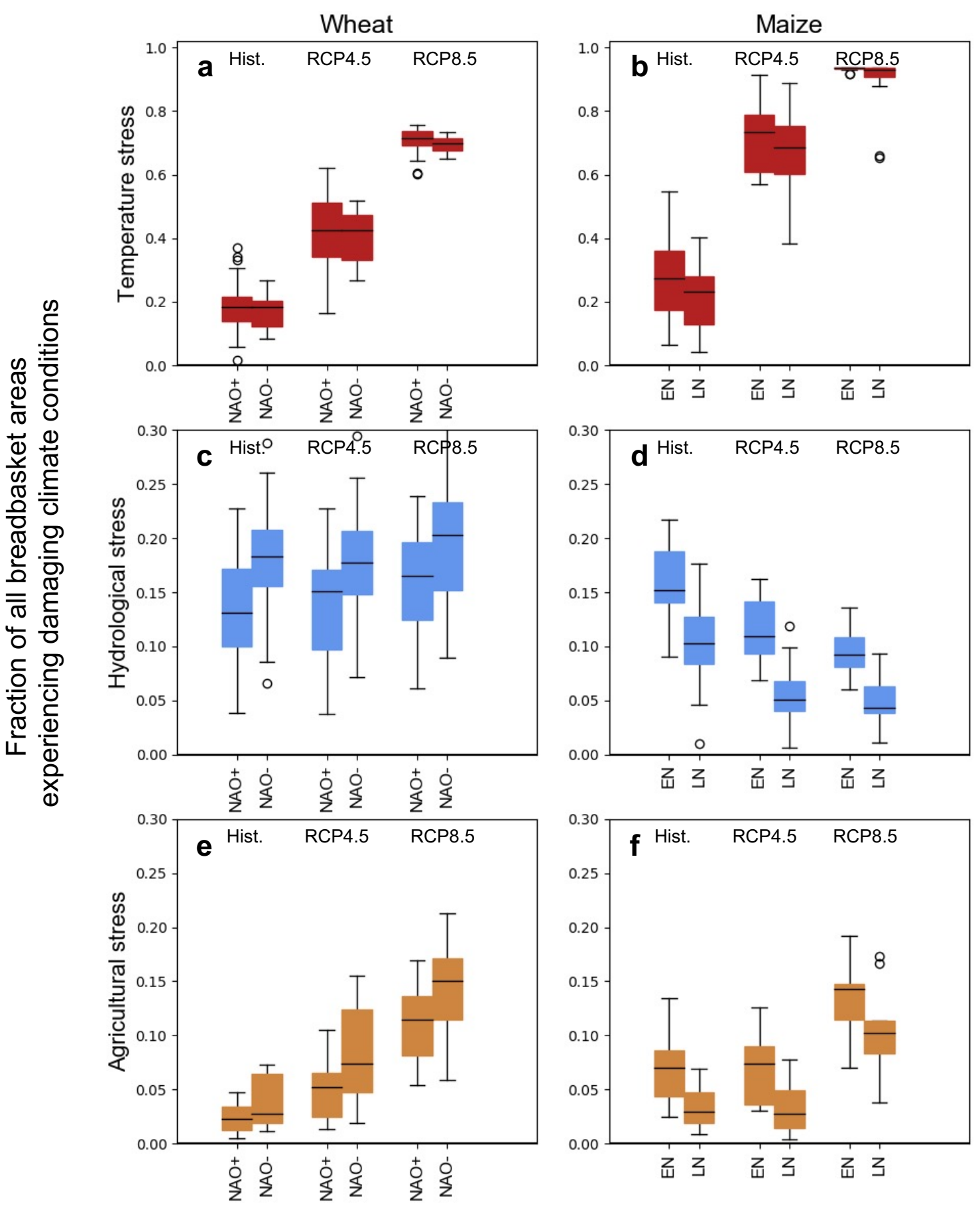

Figure 6: Observed and projected climate stress in breadbasket regions. Fraction of all breadbasket regions experiencing temperature stress (a, b), hydrological stress (as measured by runoff; c, d), or agricultural moisture stress (as measured by surface soil moisture; e, f) in the historical period and at the end of the century in RCP 4.5 and RCP 8.5 scenarios. Opposing phases of the climate mode most relevant to multiple crop shocks is shown: for maize the El Niño Southern Oscillation, the North Atlantic Oscillation 


\section{Supplementary Files}

This is a list of supplementary files associated with this preprint. Click to download.

- CenturyYields07.26.21SupplementaryInformation.pdf 